\title{
Offering Zero-Rated Content in the Shadow of Net Neutrality ${ }^{\star}$
}

\author{
Giuseppe Colangelo** \\ Valerio Torti***
}

\begin{abstract}
Telenor case, the EU Court of Justice has for the first time interpreted the relationship between net neutrality regulation and zero-rating offers, considering the former incompatible with the offer of packages in which data traffic generated by certain applications does not count towards the consumption of the data volume purchased and whereby, once that data volume has been used up, end-users may continue to use those applications without restriction, while other applications are blocked or slowed. However, despite their incompatibility with the net neutrality principle of non-discrimination, zero-rating offers may provide benefits to consumers, fostering broadband consumption and promoting product differentiation without necessarily leading to the exclusion of content providers. Therefore, a revision of the net neutrality regulation is needed in order to assess this practice in accordance with an ex post case-by-case investigation.
\end{abstract}

KEYWORDS: Zero-rating, sponsored data, net neutrality, regulation, antitrust.

\section{Introduction}

While nowadays the attention is captured by the wave of reform proposals recently released questioning the capability of current antitrust rules to handle the emergence of large technology platforms, advocating to replace or supplement them with regulatory measures to better scrutinize new

\footnotetext{
* Date of reception: 16 December 2020. Date of acceptance: 18 January 2021. DOI: https://doi.org/10.34632/mclawreview.2021.10011.

** Jean Monnet Professor of EU Innovation Policy; Associate Professor of Law and Economics, University of Basilicata; TTLF Fellow, Stanford Law School; https://orcid.org/0000-0002-00893545; giuseppe.colangelo1975@gmail.com.

*** Post-Doctoral Research Fellow, European University of Rome.
} 
practices and business models ${ }^{1}$, it is worth acknowledging that net neutrality has been the first intervention to refuel the longstanding debate on the scope of regulation and antitrust enforcement. Moreover, net neutrality regulation has inspired the inquiries in digital markets. Indeed, these investigations are premised on the assumption that online platforms must ensure rivals a level playing field, namely fairness and contestability on the platform and on neighbouring markets, by implementing a non-discrimination/neutrality regime. In a similar vein, by imposing on broadband service providers (ISPs) non-discriminatory traffic management obligations, net neutrality regulation aims at preventing them from engaging in conducts potentially harmful to edge providers, thus considering antitrust laws unfit for this task.

For decades, the pendulum of the interplay between antitrust and regulation has swung back and forth from rivalry to complementarity. While, in the application of a "plain repugnancy" standard, US antitrust laws have long predominated over regulation ${ }^{2}$, more recently the Supreme Court has shifted the balance, giving deference to federal regulation due to expertise and cost concerns ${ }^{3}$. In the EU, the Court of Justice (CJEU) has expressed greater support for the application of antitrust rules in regulated industries. Notably, with regard to the telecommunications industry and the margin squeeze of competitors, the CJEU has ruled that the approval by a national sectoral regulator of a dominant undertaking's pricing practices cannot, as such, absolve that undertaking from responsibility under antitrust rules ${ }^{4}$.

\footnotetext{
${ }^{1}$ See e.g. Australian Competition and Consumer Commission, Digital platforms inquiry, 2019, https://www.accc.gov.au/focus-areas/inquiries-ongoing/digital-platforms-inquiry; European Commission, Proposal for a Regulation on Contestable and Fair Markets in the Digital Sector (Digital Markets Act), COM(2020) 842 final, 2020; UK Competition and Markets Authority, A New Pro-Competition Regime for Digital Markets. Advice of the Digital Markets Taskforce, 2020, https:// www.gov.uk/cma-cases/digital-markets-taskforce; U.S. House of Representatives, Subcommittee on Antitrust, Commercial, and Administrative Law, Investigation of Competition in Digital Markets, Majority Staff Reports and Recommendations, 2020, https://judiciary.house.gov/uploadedfiles/investigation_of_competition_in_digital_markets_majority_staff_report_and_recommendations.pdf.

${ }^{2}$ U.S. v. Trans-Missouri Freight Association, 166 U.S. 290 (1897); U.S. v. Philadelphia National Bank, 374 U.S. 321 (1963); Otter Tail Power Co. v. U.S., 410 U.S. 366 (1973).

${ }^{3}$ NYNEX Corp. v. Discon Inc., 525 U.S. 128 (1998); Verizon Commc'ns Inc. v. Law Offices of Curtis V. Trinko, LLP, 540 U.S. 398 (2004); Credit Suisse Securities (USA) LLC v. Billing, 551 U.S. 264 (2007); Pacific Bell Tel. Co. v. linkLine Communications, Inc., 555 U.S. 438 (2009).

${ }^{4}$ Judgement of 14 October 2010, Deutsche Telekom v. European Commission, C-280/08 P, EU:C:2010:603; Judgement of 10 July 2014, Telefónica SA and Telefónica de España SAU v.
} 
Because of their overlap in addressing market power, the choice between antitrust and regulation depends to a great extent on the trade-offs in the specific case concerned. Namely, it requires assessment of whether ex ante regulatory intervention in the market furnishes significant incremental benefits with respect to existing ex post antitrust policies of general applicability ${ }^{5}$.

In the case of net neutrality, the benefits of a regulation have been questioned in the literature, since the effects of a discriminatory regime on consumer welfare and market competition is unclear. Moreover, the incentive, and even the ability, of broadband providers to harm edge providers is uncertain. For these reasons, the advantages of an ex ante prohibition $v i s-\grave{a}$-vis an ex post case-by-case assessment are controversial. Against this backdrop, the emergence of zero-rating offers as business practice has further inflamed the broader public policy discussion on net neutrality regulation. Indeed, by excluding some traffic from overall data caps, zero-rating may be incompatible with the basic net neutrality principle of treating all traffic equally. Nonetheless, the practice also provides benefits to consumers, fostering broadband consumption and promoting product differentiation, hence suggesting that a case-by-case review could be more adequate than a blanket prohibition.

Moving from the debate over net neutrality regulation, the aim of this article is to shed light on zero-rating offers, analysing their features, economic rationales and competitive effects, in order to suggest a reconsideration of their regulation.

The article is structured as follows. Section 2 describes features and models of zero-rating offers, analysing their inconsistency with net neutrality rules and providing a comparative overview of the approaches adopted by regulatory authorities around the world. Section 3 illustrates the welfare and competitive effects of zero-rating, reviewing the economic literature which has questioned risks and concerns asserted by supporters

European Commission, C-295/12 P, EU:C:2014:2062. See also Judgement of 13 December 2018, Slovak Telekom v. European Commission, Case T-851/14, EU:T:2018:929.

${ }^{5}$ See Dennis W. Carlton and Randal C. Picker, "Antitrust and regulation", in Economic Regulation and its Reform, Nancy L. Rose (ed.), (University of Chicago Press, 2014), 24 and, more recently, Bruce H. Kobayashi and Joshua D. Wright, "Antitrust and ex-ante sector regulation", The Global Antitrust Institute, Report on the Digital Economy, (2020), 865 https:/gaidigitalreport.com, arguing that the choice between these approaches implies an analysis of their substantive differences (i.e. timing, rules versus standards), as well as of the expertise to administer a regime. 
of net neutrality. Section 4 concludes with a call for reform of the EU net neutrality regulation.

\section{The role of zero-rating offers in the net neutrality debate}

The assessment of zero-rating offers represents the last episode of the longrunning debate regarding the regulation of the internet. Indeed, the issue of differential pricing is part of the broader public policy discussion on net neutrality. Moving from the assumption that ISPs enjoy endemic market power, the aim of net neutrality is to ensure that all internet traffic is treated equally. As terminating access monopolists, ISPs are deemed gatekeepers for edge providers that seek to reach their end-user subscribers, hence they may discriminate against the former and impose restrictions on the latter. Against this background, net neutrality implies that content providers are all offered the same quality of service and that broadband providers cannot prioritize certain types of traffic. Namely, according to three ex ante bright-line rules, ISPs should be prevented from blocking content, throttling traffic, and discriminating against specific content for a fee.

In 2015, the EU adopted Regulation 2015/2120 establishing common rules to safeguard equal and non-discriminatory treatment of traffic in the provision of internet access services and related end-users' rights ${ }^{6}$. Any practices which go beyond reasonable traffic management measures, by blocking, slowing down, altering, restricting, interfering with, degrading, or discriminating between specific content, applications or services, or specific categories of content, applications, or services, are prohibited, subject to justified and defined exceptions. Notably, pursuant to Article 3, end users shall have the right to access and distribute information and content, use and provide applications and services, and use terminal equipment of their choice, irrespective of the end user's or provider's location or the location, origin or destination of information, content, application or service, via their internet access service. Further, agreements between providers of internet access services and end users on commercial and technical conditions and the characteristics of internet access services such as price,

\footnotetext{
${ }^{6}$ Regulation (EU) 2015/2120 of the European Parliament and of the Council of 25 November 2015, laying down measures concerning open Internet access and amending Directive 2002/22/EC on universal service and users' rights relating to electronic communications networks and services; and Regulation (EU) 531/2012 on roaming on public mobile communications networks within the Union, (2015) OJ L 310/1.
} 
data volumes or speed, and any commercial practices conducted by providers of internet access services, shall not limit the exercise of the aforementioned rights of end users. Finally, providers of internet access services shall treat all traffic equally when providing internet access services, without discrimination, restriction or interference, and irrespective of the sender and receiver, the content accessed or distributed, the applications or services used or provided, or the terminal equipment used.

In the US, on the other hand, the Federal Communications Commission (FCC)'s 2015 'Open Internet Order'7 was repealed in 2018 ${ }^{8}$. In 'Restoring internet freedom', the FCC reverted to its pre-2015 position, concluding that the benefits of a market-based, light-touch regime for internet governance outweigh those of utility-style, common carrier regulation. Using the former FCC Chairman's words, "there was no problem to solve. The internet was not broken in 2015. We were not living in a digital dystopia"9. Rather, according to Mr. Ajit Pai, net neutrality rules undermined investments in high-speed networks ${ }^{10}$.

Indeed, while supporters of net neutrality argue that a discriminatory regime would stifle innovation by reducing the entry of content providers and would negatively affect the welfare of end-users in terms of subscription fees, variety of content, and quality of connection ${ }^{11}$, opponents question the very economic logic of net neutrality regulation by maintaining that it would increase regulatory costs, disincentivize ISPs' investments in broadband capacity, and harm both consumers and content providers ${ }^{12}$.

\footnotetext{
${ }^{7}$ U.S. Federal Communications Commission, "Open internet order", (2015) 30 FCC Rcd 5601 https://www.fcc.gov/document/fcc-releases-open-internet-order.

${ }^{8}$ U.S. Federal Communications Commission, "Restoring internet freedom order", (2018) 33 FCC Rcd 311 https://www.fcc.gov/document/fcc-releases-restoring-internet-freedom-order.

${ }_{9}^{9}$ Ajit Pai, Statement, (2018), 1. https://www.fcc.gov/document/fcc-releases-restoring-internetfreedom-order/pai-statement.

${ }^{10}$ However, according to Christopher A. Hooton, "Testing the economics of the net neutrality debate", Telecommunications Policy 44, no. 5 (2020), net neutrality policy changes in the U.S. had no impact on telecommunication industry investment levels. See also Ingo Vogelsang, "Net Neutrality Regulation: Much ado about nothing?", Review of Network Economics 17, no. 3 (2019): 225 , considering net neutrality largely ineffective, in particular when it comes to the prohibition of fast lanes and other quality of service differentiations, and to a lesser extent, when it comes to the zero-price rule.

${ }^{11}$ See e.g. Barbara van Schewick, "Towards an economic framework for network neutrality regulation", Journal on Telecommunications \& High Technology Law 5, no. 2 (2006): 329.

${ }^{12}$ See e.g. Michael L. Katz, "Wither U.S. Net Neutrality Regulation?", Review of Industrial Organization 50 (2017): 441, finding a substantial tension between the Regulation and the objective of promoting consumer choice and sovereignty, and noting that the Internet has never been
} 
Moreover, doubts have been raised about the empirical evidence supporting the framework ${ }^{13}$ and the incremental benefits that regulation may offer over existing antitrust rules of general applicability ${ }^{14}$.

Nonetheless, as correctly argued in the economic literature, the economic consequences of net neutrality regulation depend on the precise policy choice, how it is implemented and how long-run economic trade-offs play out ${ }^{15}$. For instance, it has been maintained that strict net neutrality (i.e. all incoming traffic is treated equally by the ISP, and content providers are not charged for delivery of traffic) often leads to socially inefficient allocation of traffic and traffic inflation ${ }^{16}$, and that strong forms of net neutrality (i.e. the rules prohibiting content-based discrimination are applied to the ISP's pricing with respect to both consumers and content providers) may harm efficiency by distorting both ISPs and content providers' investment and service-quality choices ${ }^{17}$. Further, it has been observed that net neutrality rules protect innovation done at the edge by small content providers, while prioritization increases both infrastructure core investment and welfare only if it sufficiently stimulates innovation from the large content provider $^{18}$, and it has been argued that the effects of net neutrality regulation on innovation incentives of major content providers substantially depend on the relative size of the ISPs' network capacity vis-à-vis major

and is not designed to be neutral; Christopher S. Yoo, "Beyond network neutrality", Harvard Journal of Law \& Technology 19, no. 1 (2005): 1, considering network neutrality as a misnomer which may reinforce the sources of market failure in the last mile and dampen incentives to invest in alternative network capacity.

${ }^{13}$ See e.g. Thomas W. Hazlett and Joshua D. Wright, "The effect of regulation on broadband markets: Evaluating the empirical evidence in the FCC's 2015 'Open internet' order", Review of Industrial Organization 50 (2017):487; Timothy J. Tardiff, "Net neutrality: Economic evaluation of market developments", Journal of Competition Law \& Economics 11, no. 3 (2015): 701.

${ }^{14}$ See e.g. A. Douglas Melamed and Andrew W. Chang, "What thinking about antitrust law can tell Us about net neutrality", Colorado Technology Law Journal 15, no. 1, (2016): 93; Maureen K. Ohlhausen, "Antitrust over net neutrality: Why we should take competition in broadband seriously", Colorado Technology Law Journal 15, no. 1 (2016): 119.

${ }^{15}$ Shane Greenstein, Martin Peitz, and Tommaso Valletti, "Net neutrality: A fast lane to understanding the trade-offs", The Journal of Economic Perspectives 30, no. 2 (2016): 127.

${ }^{16}$ Martin Peitz and F. Schuett, "Net neutrality and inflation of traffic", International Journal of Industrial Organization 46 (2016): 16.

${ }^{17}$ Joshua Gans and Michael L. Katz, "Weak versus strong net neutrality: Corrections and extensions”, Journal of Regulatory Economics 50 (2016): 99.

${ }^{18}$ Carlo Reggiani and Tommaso Valletti, "Net neutrality and innovation at the core and at the edge”, International Journal of Industrial Organization 45 (2016): 16. 
content providers' bandwidth usage ${ }^{19}$. Finally, while most studies assume a monopolistic market structure at the ISP level, it has been noted that, in a model with competing ISPs, a switch from the net neutrality regime to the alternative discriminatory regime would be beneficial in terms of investments, innovation and total welfare ${ }^{20}$.

Against this backdrop, zero-rating has attracted specific and increasing attention as an emerging business practice. Representing a form of price discrimination, zero-rating may be incompatible with the basic net neutrality principle of treating all traffic equally. Indeed, by allowing ISPs to make the consumption of some data packets more expensive than others, zero-rating shares the same rationale as paid prioritization, which allows ISPs to deliver content at different speeds, i.e. to discriminate in terms of quality. In more detail, under a zero-rating arrangement, an ISP is able to charge different marginal rates for different types of content, whereas users purchase a package with a monthly data cap which is not affected or lowered by usage of specific content. In this context, users may also benefit from "sponsored data", when edge providers offer their content to consumers on a zero-rated basis by arranging to "buy down" or "sponsor" the data used by these consumers. In the case where data plans are sponsored, it is the content provider who pays ISPs for the users' data consumption as related to that content provider's services and applications. Furthermore, zero-rating offers may also be coupled with throttling, which takes place in the case where the broadband service provider decides to offer zero-rated content only when the download speed of this content is simultaneously reduced, in comparison to the download speed applicable to non-zerorated services and applications.

Four different models have been identified. Under the "no payment - no exclusivity" scheme, the ISP does not receive any payment and will offer zero-rated packages non-exclusively to all applications within a class, provided that certain technical rules are complied with. A second model is based on a "no payment - some exclusivity" rule, which sees the ISP partnering with selected content providers to zero-rate particularly popular

\footnotetext{
${ }^{19}$ See Jay P. Choi, Doh-Shin Jeon, and Byung-Cheol Kim, "Net neutrality, network capacity, and innovation at the edges", The Journal of Industrial Economics 66, no. 1 (2018): 172, arguing that if the ISPs' network capacity is relatively large, the prioritization reduces the investment as content provider's investment and prioritization form substitutes. Although with limited capacity, the prioritization can facilitate the entry of congestion-sensitive content.

${ }^{20}$ Marc Bourreau, Frago Kourandi, and Tommaso Valletti, "Net neutrality with competing internet platforms", Journal of Industrial Economics 63, no. 1 (2015): 30.
} 
applications or content having civic value. A third scheme refers instead to the already examined sponsored data practice and, finally, the ISP may be a vertically integrated firm operating at both levels, self-supplying (and zero-rating) its own services and applications.

Overall, evidence suggests that, in the light of their lower costs, zerorating offers have become significantly more attractive to consumers as compared to non-zero-rated packages. Such advantageous offers clearly have an impact on users' choice of ISPs, of the content they access, and the amount of data consumption. Consequently, zero-rating practices do affect rivalry amongst broadband providers and content providers.

But how have zero-rating practices been considered by regulatory authorities at the international level?

From a comparative perspective, the various approaches adopted in the US, Canada and India deserve specific attention. For instance, a ban on all zero-rating plans was issued in 2016 by the Telecom Regulatory Authority of India, which prohibited broadband access providers from applying differential pricing of data plans on the basis of content, applications or services being accessed by an end user ${ }^{21}$. By the same reasoning, net neutrality rules preventing discrimination or interference with data are endorsed by India's Department of Telecommunications, with some exceptions ${ }^{22}$. Indeed, in this regard the authority has specified that those provisions do not apply to "critical IoT services" or "specialized services" (e.g., concerning autonomous vehicles and remote surgery operations).

A slightly different approach has been adopted by the Canadian RadioTelevision and Telecommunications Commission (CRTC), which has not implemented an absolute ban on zero rating offers but rather opted for a case-by-case analysis. In practice, however, the Canadian regulatory authority has so far taken a rigid approach towards zero-rating and paid prioritization practices, de facto prohibiting both. More specifically, although the Canadian Telecommunication Act was written in the 90's in a technology-neutral manner, the CRTC was able to interpret the Act in accordance with net neutrality principles and implement ad hoc regulatory policies, mainly relying on those provisions of the Act prohibiting

\footnotetext{
${ }^{21}$ Telecom Regulatory Authority of India, Prohibition of Discriminatory Tariffs for Data Services Regulations, 2016. https:/www.trai.gov.in/notifications/press-release/trai-releases-prohibitiondiscriminatory-tariffs-data-services.

${ }^{22}$ Department of Telecommunications of India, Regulatory Framework on Net Neutrality, 2018. https://dot.gov.in/net-neutrality.
} 
unjust discrimination and undue or unreasonable preference or disadvantage by telecommunications common carriers ${ }^{23}$. Moreover, during the course of 2017, the CRTC strengthened its commitment to net neutrality by introducing a new framework for differential pricing practices, with specific regard to the zero-rating or discounting of retail Internet data traf$\mathrm{fic}^{24}$. Against this background, the authority confirmed that ISPs should treat data traffic equally and stated that differential pricing practices may be reviewed and assessed in the light of different factors. Among these, the CRTC would make specific efforts to explore whether data is treated equally regardless of its source or nature, whether practices are exclusive to certain customers or certain content providers, whether financial compensation is involved, and what the impact is on internet openness or innovation. In developing such assessment, the Canadian regulatory authority may examine whether practices rely on market forces to the maximum extent feasible, whether they try to remove barriers to entry, whether the measures are efficient and proportionate to the aim of preventing violations of the unjust discrimination standard, and whether they are applied in a competitively neutral manner.

A more tortuous path has characterized the assessment of differential pricing practices in the US. Under the 2015 "Open Internet Order" a caseby-case approach has been promoted in exploring zero-rating offers, while in contrast paid prioritization was explicitly banned. Behind this position, there was the shared belief that zero-rating practices do not automatically raise concerns but could in some instances lead to consumer and competitive benefits, such as increased competition, by facilitating the availability of over the top (OTT) services ${ }^{25}$. A per se approach in examining zero-rating was therefore excluded. However, besides the three bright-line rules, the FCC mandated a "general conduct rule" to be used to stop new and novel threats to the internet and avoid potential harm to consumers, competition and innovation. In this regard, zero-rating practices could be assessed on an ex-post basis under an "unreasonableness standard", which implied the need to evaluate whether an unreasonable interference or

\footnotetext{
${ }^{23}$ Telecommunications Act, S.C. 1993, chapter 38, sections 27(2) and 36. https://laws-lois.justice. gc.ca/PDF/T-3.4.pdf.

${ }^{24}$ Canadian Radio-television and Telecommunications Commission, Telecom Regulatory Policy, 2017. https://crtc.gc.ca/eng/archive/2017/2017-104.htm.

${ }^{25}$ Wireless Telecommunications Bureau, Policy Review of Mobile Broadband Operators' Sponsored Data Offerings for Zero-Rated Content and Services, 2017. https://www.fcc.gov/document/releasereport-policy-review-mobile-zero-rating-practices.
} 
disadvantage of a zero-rating practice affected end-users' rights to access content or edge providers' ability to make content available to end-users. Accordingly, the FCC launched investigations on certain sponsored data offerings by vertically integrated carriers which may have harmed consumers and competition in downstream markets by unreasonably discriminating in favour of their own affiliates.

In 2017, a new composition of the FCC eventually voted to repeal the "Open Internet Order" and abolish net neutrality protections, hence zerorating is currently permitted in the US.

\subsection{The European scenario: BEREC Guidelines}

In the EU scenario, Regulation 2015/2120 has introduced rules similar to those that were in place in the US. Basically, the Regulation has, on the one hand, prohibited paid prioritization and, on the other, tolerated zero-rating under limited specific conditions. In this context, the Body of European Regulators for Economic Communications (BEREC) has contributed to the consistent application of the Regulation by publishing the "Guidelines on the Implementation by National Regulators of European Net Neutrality Rules"26. This document has recently been updated, i.e. the "Guidelines on the Implementation of the Open Internet Regulation"27.

In essence, these Guidelines advice on the implementation of the obligations of national regulators, including the obligations to closely monitor and ensure compliance with the rules to safeguard equal and non-discriminatory treatment of traffic in the provision of internet access services and related end users' rights. In other words, they represent recommendations to national regulators and should contribute to a coherent application of Regulation 2015/2120 and to the establishment of regulatory certainty for all stakeholders. Besides the Guidelines, BEREC also regularly publishes a Report on the implementation of the Regulation and its Guidelines, which fundamentally gives an overview of national regulatory authorities' activities in the course of implementing the net neutrality provisions ${ }^{28}$. Such a Report, inter alia, summarizes information obtained by national regulators about net neutrality cases and investigations which have arisen in

\footnotetext{
${ }^{26}$ BEREC, Guidelines on the Implementation by National Regulators of European Net Neutrality Rules, BoR, 2016, 127.

${ }^{27}$ BEREC, Guidelines on the Implementation of the Open Internet Regulation, BoR, 2020, 112.

${ }^{28}$ BEREC, Report on the Implementation of Regulation (EU) 2015/2120 and BEREC Net Neutrality Guidelines, BoR, 2020, 166.
} 
the period under examination, and about any implemented monitoring methods. For instance, the 2020 BEREC Report has highlighted that zerorating of music streaming services, video streaming / IPTV services, social media services and voice and short messages are typically the most often identified examples, as reported by various national regulatory authorities.

The Guidelines mandate a case-by-case treatment of zero-rating offers by national regulatory authorities, while explicitly banning paid prioritization. In particular, zero-rating is interpreted as a commercial practice whereby "the data traffic associated with a particular application or category of applications does not count towards the general data cap in place on the Internet access service" 29 . As the argument goes, there are other commercial practices also involving differentiated pricing which could have different effects on the Open Internet and on end-users' rights as protected under Regulation 2015/2120. Among these, the Guidelines refer to sponsored data, or subscriptions offering end users the option to choose a zero-rated offer from a range of applications with operator-defined categories, provided that these practices may involve a limited or unlimited amount of data ${ }^{30}$. Zero-rating offers are prohibited in the case where the data cap is reached and all other content or applications are throttled or blocked, except for zero-rated content or applications: indeed, such practice would clearly contrast with Article 3(3) of the Regulation and with the overall objective of safeguarding equal and non-discriminatory treatment of traffic ${ }^{31}$.

In this context, the Guidelines call attention to the case where zerorating concerns only certain applications (e.g. the most popular video or music streaming applications) rather than an entire class of applications (a so called "open zero-rating programme"). In the former case, the effects of zero-rating are more likely to undermine the essence of end users' rights or lead to circumstances where end users' choice is materially reduced in practice $^{32}$. In this regard, national regulators should pay particular attention to the extent to which a zero-rating programme is open to all content providers of a specific category and to whether the programme access terms are fair, reasonable, non-discriminatory and transparent ${ }^{33}$.

\footnotetext{
${ }^{29}$ BEREC, Guidelines on the Implementation of the Open Internet Regulation, para. 40.

${ }^{30}$ Ibid., para. 40.

${ }^{31}$ Ibid., para. 41.

${ }^{32}$ Ibid., para. 42.

${ }^{33}$ Ibid., para. 42(b).
} 
More generally, a comprehensive assessment of the commercial and technical conditions is suggested, on the basis of a number of additional factors which may eventually contribute to a material reduction in end users' choice and hence to a limitation of the exercise of end users' rights under Article 3(2) of the Regulation. Notably, the Guidelines suggest that, in exploring the scope and effects of zero-rating, national regulators should look at the objectives of the Regulation, the aim of ensuring the continued functioning of the internet ecosystem as an engine of innovation, and the market positions of the ISPs and content providers involved ${ }^{34}$. Furthermore, national regulatory authorities should consider the effects on consumer and business customer end-user rights (e.g. whether the range of applications which end users can choose from is reduced and whether end users are incentivized to use certain applications), the effects on content providers end-user rights (e.g. whether such providers are materially discouraged from entering the market or forced to leave the market), as well as the scale of the practice and the presence of alternatives ${ }^{35}$. In developing the assessment, certain considerations should also be taken into account. In particular, the Guidelines point to the fact that "commercial practices applying a higher price to the data associated with a specific application or class of applications are likely to limit the exercise of endusers' rights because of the potentially strong disincentive created to the use of the application(s) affected, and consequent restriction of choice"36. At the same time, this may lead to incentivize end users to use the zerorated applications or category of applications. Consequently, the development of new applications may eventually be limited or discouraged. From BEREC's standpoint, price differentiation should be looked upon with suspicion especially when it is applied between individual applications within a category: this case is interpreted as being more likely to impact on the continued functioning of the internet ecosystem as an engine of innovation than the case where price differentiation is applied between classes of applications. ${ }^{37}$

\footnotetext{
${ }^{34}$ Ibid., para. 46.

${ }^{35}$ Ibid., para. 46.

${ }^{36}$ Ibid., para. 48.

${ }^{37}$ Ibid., para. 48.
} 


\subsection{The national implementation of net neutrality rules}

Against this background, it is worth providing illustrative cases of the activities of some national regulatory authorities (NRAs) in the course of implementing the net neutrality provisions.

The major zero-rating offers investigated by the German Federal Network Agency for Electricity, Gas, Telecommunications and Railway (Bundesnetzagentur) are the tariff option "StreamOn" offered by Deutsche Telekom and "Vodafone Pass" by Vodafone ${ }^{38}$.

Under the former, customers can add to their mobile communications plan the free StreamOn option, which ensures that the data volume generated from audio and video streaming of the Deutsche Telekom's content partners' services is not offset against the data allowance included in the mobile communications tariff agreed in the contract for use of the internet connection provided via mobile communications but, once it has been used up, the transmission speed in general is reduced. Although participation is open to any audio or video content provider, the provider is required to conclude an agreement with Deutsche Telekom and meet the requirements set out in the general terms and conditions for content providers. Moreover, the end-user also agrees to limitation of the bandwidth for video streaming, irrespective of whether the video streaming service is provided by content partners or by other providers. As a result, the Bundesnetzagentur has prohibited the use of video throttling as part of StreamOn, stating that there is no objective technical reason to reduce the data transmission rate.

Deutsche Telekom agreed to revise its general terms and conditions to ensure an open, transparent and non-discriminatory participation of content providers in StreamOn, but objected that the bandwidth limitation under the optional add-on does not amount to a violation of net neutrality rules. In January 2020, the Administrative Court of Cologne lodged a request for a preliminary ruling asking the CJEU to clarify several doubts, e.g. whether bandwidth limitation qualifies as the slowing down of one category of service within the meaning of Article 3(3) of the Regulation, whether it represents a permissible traffic management measure, whether it fulfils the condition that traffic management measures must be based on

\footnotetext{
${ }^{38}$ Federal Network Agency for Electricity, Gas, Telecommunications and Railway, Net Neutrality in Germany. Annual Report 2017/2018, 2018. https://www.bundesnetzagentur.de/SharedDocs/ Downloads/EN/Areas/Telecommunications/Companies/MarketRegulation/NetNeutrality/ NetNeutralityInGermanyAnnualReport2017_2018.pdf?__blob=publicationFile\&v=2.
} 
objectively different technical quality of service requirements of specific categories of traffic and whether, in a situation such as that at issue in this proceeding, it qualifies as a restriction of end-users' rights ${ }^{39}$.

Vodafone's zero-rating offer, instead, acts as an add-on option to its Red and Young tariffs and provides passes from the categories audio, video, chat and social to be added. Such passes allow consumers to use specific mobile communications services via apps selected by the defendant for those services without the related data volumes being counted towards the basic data volumes specified in their respective mobile communications tariff. Vodafone Pass is designed in such a way that content providers without an app cannot participate and, although video throttling is not implemented, Vodafone has contractually reserved the right to do so. The Bundesnetzagentur has objected that the reservation of video throttling and the conditions of participation for content providers were at odds with net neutrality rules.

Additional concerns have been raised with regard to another specific provision of the service. Indeed, according to Vodafone's general terms and conditions, data consumption upon usage via tethering (i.e. the use of internet access service with other terminal equipment via hotspot) is counted towards the tariff data volume. Notably, it is disputed whether this clause constitutes a limitation within the meaning of Article 3(2) of the net neutrality Regulation. It can be argued that the clause at stake does not prohibit tethering, but merely restricts it in economic terms. At the same, however, when assessing whether an ISP limits the exercise of rights of end-users, NRAs may consider to what extent end-users' choice is restricted by the agreed commercial and technical conditions or the commercial practices of the ISP. Accordingly, any practice of making tethering economically less advantageous may be considered a limitation, even if there is no technical or contractual exclusion of tethering. For these reasons, in January 2020 the Higher Regional Court of Düsseldorf decided to submit a request for a preliminary ruling to the $\mathrm{CJEU}^{40}$.

In Italy, the Communications Authority (AGCOM) has addressed WindTre zero-rating offers ("Wind Veon" and "Music by 3") concerning messaging and music applications ${ }^{41}$. The AGCOM has considered these offers

\footnotetext{
${ }^{39}$ Case C-34/20, Telekom Deutschland GmbH v. Bundesrepublik Deutschland.

${ }^{40}$ Case C-5/20, Bundesverband der Verbraucherzentralen und Verbraucherverbände v. Vodafone $\mathrm{GmbH}$.

${ }^{41}$ Italian Communications Authority, 15 March 2017, Decision No. 123/17/CONS.
} 
in breach of the net neutrality Regulation, observing a discrimination of the general purpose traffic, which is blocked or slowed down, compared to the zero-rated traffic, which flows on without locks or slowdowns.

The Netherlands Authority for Consumers and Markets (ACM) has investigated the "Data-free Music" service of T-Mobile, which offers unlimited music streaming to its customers (with data plans of at least 6 GB) ${ }^{42}$. The zero-rating offer is found not to be breaching the European rules on net neutrality. Indeed, the service is non-discriminatory: every musicstreaming service is able to join the service, hence providers of content and applications are treated equally within the category of music streaming services. In addition, music streaming services do not encounter any substantial barriers to entry in order to become affiliated with the Data-free Music service. Furthermore, the service does not reduce end-users' choice. In fact, because the service is open to all public music streaming services, end-users can choose from a large range of music streaming services. Endusers are also able to exert influence over the music streaming services affiliated with the Data-free Music service, since they are able to make suggestions to T-Mobile regarding any other music streaming service they wished to see affiliated. Finally, the fact that the service is only available to T-Mobile customers with data plans of $6 \mathrm{~GB}$ or more is another indication that end-users' rights are not limited. As highlighted by the BEREC Guidelines, the smaller the data plan to which zero-rating is applied, the greater the impact of zero-rating on the choice of end-users.

It is worth mentioning that, initially, ACM argued that the service violated the Dutch Telecom Communications Act, hence it ordered T-Mobile to stop offering and providing the Data-free Music service. Later, the District Court of Rotterdam ruled that, although zero-rating is categorically prohibited by the national law, the Dutch prohibition did not apply because the Netherlands are not authorized to regulate on a matter subject to the European net neutrality Regulation ${ }^{43}$. Moreover, the Court noted that the latter does not include a categorical prohibition of zero-rating.

\footnotetext{
${ }^{42}$ The Netherlands Authority for Consumers and Markets, 26 September 2017, Case No. 17.0475.53. See also Authority for Consumers and Markets, T-Mobile can continue to offer its Data-free Music service, 2017, https://www.acm.nl/en/publications/t-mobile-can-continue-offer-its-data-free-music-service.

${ }^{43}$ District Court of Rotterdam, 20 April 2017, Case No. ROT 17/468, ROT 17/1160 and ROT 17/1932, T-Mobile Netherlands B.V. v. ACM.
} 
The UK NRA has been involved in the analysis of several zero-rating offers.

Notably, in 2017 Ofcom has reviewed "Three/GoBinge" (which zerorated certain music and video streaming applications), "Vodafone/VOXI" (which initially zero-rated selected social media and messaging applications and later also included selected video and music applications), and "Vodafone/Passes" offers (which zero-rated data for selected applications in different categories, i.e. chat, social, music and video ${ }^{44}$. The Authority found that Three/GoBinge zero-rated offer did not raise sufficient competition-related issues because it did not include traffic management practices, unfair treatment, or a sub-internet service type offer. Conversely, Ofcom opened a formal assessment of the Vodafone Passes and VOXI products, which however were related to the traffic management practices employed alongside the zero-rating rather than the zero-rating of content per se. Indeed, Vodafone/VOXI and Vodafone/Passes were found to employ a traffic management practice that restricts resolution of the video available, namely enabling standard definition video to be available in conjunction with these zero-rated products, even where the original content is made available by the content provider in higher definition formats. Ofcom's concerns were primarily that Vodafone's measures did not appear to be based on objectively different quality of service requirements and that they were in place permanently.

In 2019, Ofcom closed its review of "EE Music and Video Passes" and "Sky Watch" offers ${ }^{45}$. According to the former, customers could purchase monthly Music and Video Passes which allowed zero-rate some applications (Netflix, Amazon Prime Video, BT Sport, MTV Play and TV Player with regards to the Video Pass; Apple Music, Deezer and Tidal with regards to the Music Pass). Given that EE ensured that both Passes were open platforms, Ofcom decided not to take further action, concluding that the open platform mitigated any potential innovation risk and that the essence of end-user rights did not appear to be undermined by the offer ${ }^{46}$. The Sky Watch offer, instead, allowed Sky Mobile customers

\footnotetext{
${ }^{44}$ Ofcom, Monitoring compliance with the EU Net Neutrality Regulation, 2018. https://www.ofcom. org.uk/research-and-data/internet-and-on-demand-research/net-neutrality.

${ }^{45}$ Ofcom, Monitoring compliance with the EU Net Neutrality Regulation, 2020, https://www.ofcom. org.uk/research-and-data/internet-and-on-demand-research/net-neutrality.

${ }^{46}$ According to Ofcom, the impact of the offer at issue is limited. Indeed, while EE's Passes are likely to be attractive to consumers who already have subscribed to one of the content services included in Passes and their data allowance is quite low, it may reinforce consumers' preference
} 
having a Sky TV package to watch Sky TV and use Sky apps without this counting toward their general data allowance. Further, apps that did not require a subscription were zero-rated for all Sky Mobile customers. Yet, although Ofcom considered the offer had no material effect on end-users, it decided to keep a watching brief on whether the practice of zero-rating content from vertically integrated companies became more generalised. Indeed, the NRA argued that the Sky Watch offer raised some concerns that could potentially affect end-users' choices and circumvent the provisions safeguarding open internet access by reinforcing Sky TV's market position within the UK pay TV market. Moreover, the offer was closed and other ISPs were unlikely to offer the same deal as Sky Mobile in the foreseeable future. Finally, data involved (e.g. live streaming sports fixtures) were heavy, hence their zero-rating could act as an incentive to use Sky applications over non-Sky applications.

\subsection{The Telenor judgement}

Given the EU regulatory framework on zero-rating practices, the Telenor judgment deserves a thorough examination as it represents the first case decided by the CJEU on the interpretation of the Regulation ${ }^{47}$.

Telenor is a major player in the ICT sector, providing internet access services including two specific packages ("MyChat" and "MyMusic"). Within these two programmes, Telenor identified a number of services and applications offered to its customers at a zero tariff, which means the use of those services and applications did not contribute to the consumption of the purchased data limit. Further, under these zero-rating offers, subscribers could continue to freely use those services and applications even when all data volume was used up, whereas measures blocking or slowing down data traffic were applied to the other available (non zero-rated) applications and services. The Hungarian National Media and Communications Office, after exploring the scope of the cited offers, found that those packages introduced traffic management measures which did not comply with the obligation of equal and non-discriminatory treatment laid down in Art. 3(3) of the net neutrality Regulation. Further, it stated that, in order to assess whether such traffic management measures were compatible with

\footnotetext{
towards the included services to some extent. However, customers using these offers, in particular customers who seek out and pay for Passes, are also likely to be on plans of at least 10GB or more. ${ }^{47}$ Judgement of 15 September 2020, Telenor Magyarorszag Zrt v. Nemzeti Media es Hirkozlesi Hatosag Elnoke, C-807/18 and C-39/19, EU:C:2020:708.
} 
Art. 3(3), it was not necessary to examine how those measures impacted on the exercise of end-users' rights as described in Art. 3(1) of the Regulation. In bringing proceedings against those decisions before a national court, Telenor submitted that its zero-rated offers were part of agreements concluded with its customers and therefore could only be covered by Art. 3(2) of the Regulation. From Telenor's standpoint, Art. 3(3) could not have applied as that provision is directed solely at traffic management measures implemented unilaterally by ISPs. On a further note, the Hungarian company added that, in order to assess whether those offers were compatible with Art. 3(3) of the Regulation, it was in any event necessary to examine their effects on the exercise of end-users' rights. Accordingly, Telenor concluded that the "MyChat" and "MyMusic" programmes could not be considered incompatible with Art. 3(3) of the Regulation just because they established traffic management measures not complying with the duty to treat all traffic in an equal and non-discriminatory manner.

In the light of the divergent interpretations given by the parties, the Hungarian national court decided to refer a number of questions to the CJEU concerning the resolution of novel legal issues related to Art. 3 of the Regulation. Notably, the referring court remarked that, looking at the wording of the paragraphs of Art. 3, it was not possible to determine whether packages made available by an ISP through agreements concluded with its customers and which provide (i) that those customers may benefit from a zero tariff enabling them to use certain specific applications and services without restriction, without that use being deducted from the data volume purchased, and (ii) that once that data volume has been used up, measures blocking or slowing traffic are to be applied to the other applications and services available, fall within the scope of Art. 3(2), Art. 3(3), or Art. 3(2) and (3) of the Regulation. In addition, the referring court also stated that it was not possible to ascertain from the wording of Art. 3(2) and (3) what methodology must be applied in order to determine whether that conduct is compatible with Regulation 2015/2120.

After a careful assessment of the wording of Article 3 (and related Recitals) of the Regulation, the CJEU argued that the conclusion of agreements on a significant part of the market combining zero-rated packages and measures blocking or slowing down non-zero-rated traffic may result in limiting the exercise of end-users' rights, in clear contrast with Art. 3(2). These types of programmes are liable, on the one hand, to reduce the usage of services or applications not benefiting from the zero-rated plan 
and, on the other, to increase the use of the favoured services or applications. Therefore, the CJEU eventually concluded that the type of packages under consideration must be interpreted as incompatible with Art. 3(2) of the Regulation, read in conjunction with Art. 3(1), where those packages, agreements and measures blocking or slowing down traffic limit the exercise of end-users' rights ${ }^{48}$. In addition, they are also incompatible with Art. 3(3) of the Regulation where those measures blocking or slowing down traffic are based on commercial considerations, and not on objectively different technical quality of service requirements for specific categories of traffic. Notably, in order to make a finding of incompatibility under Art. 3(3), the CJEU stated that no assessment of the effect of those measures on the exercise of end-users' rights is required, fundamentally following the Opinion of the Advocate General Sanchez Bordona. Indeed, Article 3(3) does not lay down a similar requirement in order to explore whether traffic has been treated equally and non-discriminatorily. This provision, in the Court's view, should play a central role in the competent national authorities' and courts' assessment ${ }^{49}$.

On the whole, while backing a case-by-case approach, the CJEU has taken a clear stand in support of EU net neutrality rules, arguing that the type of offers under examination may likely lead to an exponential erosion of the rights enshrined in the Regulation.

\section{Competitive implications of zero-rating}

As shown in the Telenor judgment, by excluding some traffic from overall data caps zero-rating may be incompatible with the net neutrality principle of non-discrimination. Nonetheless, at first glance the practice also provides benefits to consumers fostering broadband consumption and promoting product differentiation ${ }^{50}$. Moreover, several studies question the risks and the concerns asserted by supporters of net neutrality, suggesting that a case-by-case review is more adequate than a blanket prohibition of zero-rating offers.

\footnotetext{
${ }^{48}$ Ibid., paras. 30-46.

${ }^{49}$ Ibid., paras. 47-53.

${ }^{50}$ However, see Olivier Sylvain, "Integrative information platforms: The case of zero-rating", Georgetown Law Technology Review 2, no. 2 (2018): 360, arguing that regulatory regimes which permit zero-rating are troubling to the extent that they fail to redress disparities in users' engagement in the networked information economy.
} 
Notably, Gautier and Somogyi show that neither prioritization nor zerorating lead to the exclusion of content providers and that the ISP will privilege the weak content provider, even if the former is integrated with a strong content provider ${ }^{51}$. Furthermore, according to Hoernig and Monteiro, ISPs can use zero-rating to better exploit network effects on certain services and to raise the number of subscriptions ${ }^{52}$. From this perspective, zerorating represents a means to raising consumer expectations about other subscribers' usage, which in turn increases their willingness to subscribe in the first place. Moreover, Jeitschko et al. argue that zero-rating and vertical integration are complementary in improving social welfare and that allowing content providers to pay for zero-rating via a sponsored data plan raises welfare by inducing the ISP to zero-rate more content ${ }^{53}$.

By showing that sponsored data plans boost consumption of high-value content and decrease the networks' incentives to exclude low-value content, Jullien and Sand-Zantman maintain that the welfare effect of allowing this price discrimination depends on the proportion of content targeted and the value of contents ${ }^{54}$. Indeed, while zero-rating plans improve welfare when they screen free content from paid content, this may not be the case when they are used to screen similar types of content. Therefore, a ban on zero-rating reduces welfare if the proportion of low-benefit content is large, but it raises welfare if the value of low-benefit content is not too low.

Looking at the consumer side, Inceoglu and Liu show that zero-rating plans allow ISPs to fine-tune consumers' consumption patterns and offer a more effective method of price discrimination ${ }^{55}$. Therefore, instead of

\footnotetext{
${ }^{51}$ Axel Gautier and Robert Somogyi, "Prioritization vs. zero-rating: Discrimination on the internet", International Journal of Industrial Organization 73 (2020). According to the Authors, the ISP will choose prioritization when traffic is highly valuable for content providers and congestion is severe, and zero-rating in all other cases (low congestion and/or low value of traffic): indeed, the ISP prefers to discriminate in price rather than in quality, thus it will choose prioritization only if it receives a large payment from the prioritized content provider.

${ }^{52}$ Steffen Hoernig and Francisco Monteiro, "Zero-rating and network effects", Economics Letters 186 (2020).

${ }^{53}$ Thomas D. Jeitschko, Soo J. Kim, and Aleksandr Yankelevich, "Zero-rating and vertical content foreclosure", DICE Discussion Paper No. 317 (2019), https://www.econstor.eu/bitstr eam/10419/200151/1/1668746867.pdf.

${ }^{54}$ Bruno Jullien and Wilfried Sand-Zantman, "Internet regulation, two-sided pricing, and sponsored data”, International Journal of Industrial Organization 58 (2018): 31.

${ }^{55}$ Firat Inceoglu and Xingyi Liu, "Multiproduct price discrimination with quantity limits: An application to zero-rating", Economics Letters 180 (2019): 41.
} 
using zero-rating to affect competition among content providers, ISPs can rely on it to price-discriminate between different types of consumers in an environment of multiproduct demand. Moreover, this may increase the investment of ISPs in network capacity and improve social welfare. More generally, as noted by Yoo, zero-rating is just a form of service differentiation which, from an economic perspective, can benefit both end users and ISPs by allowing the former to tailor their internet service and the latter to specialize in particular types of service ${ }^{56}$. In this way zero-rating grows internet adoption rates as well ${ }^{57}$.

Providing an economic assessment of zero-rating offers, Krämer and Peitz call for a revision of the EU net neutrality Regulation since the diversity of different zero-rated offers makes it necessary to follow a case-by-case analysis ${ }^{58}$. Notably, if activation and deactivation are easy and instantaneous, a sound economic theory of harm for consumers will in many cases be hard to establish and, similarly, if access to a partnership programme is easy, low-cost, and non-discriminatory, harm on the content provider side will be difficult to establish. In a similar vein, Gerpott argues that, in many instances, interests of end customers and application providers, as well as those of politicians seeking to promote the competitive dynamics on mobile Internet access service and application markets, are best served if regulatory authorities tolerate zero-rating and check for potential harmful effects after their market launch ${ }^{59}$.

Finally, analysing zero-rated offers in Europe, the study conducted by DotEcon, Aetha Consulting and Oswell and Vahida on behalf of the European Commission has found that the nature of these offers differs dramatically among countries and that there is little evidence of exclusivity/commercial arrangements between ISPs and content providers regarding zero-rating ${ }^{60}$. Notably, the research has found no situation in which all

\footnotetext{
${ }^{56}$ Christopher S. Yoo, "Avoiding the pitfalls of net uniformity: Zero rating and non-discrimination", Review of Industrial Organization 50 (2017): 509.

${ }^{57}$ See also Arturo J. Carrillo, "Having your cake and eating it too? Zero-rating, net-neutrality, and international law”, Stanford Technology Law Review 19 (2016): 364.

${ }^{58}$ Jan Krämer and Martin Peitz, "A fresh look at zero-rating”, Telecommunications Policy 42, no. 7 (2018): 501.

${ }^{59}$ Torsten J. Gerpott, "Zero-rating arrangements of mobile internet access service providers - An analysis of the main factors shaping the need for regulatory interventions", Telecommunications Policy 42, no. 6 (2018): 489.

${ }^{60}$ DotEcon, Aetha Consulting and Oswell and Vahida, Zero-Rating Practices in Broadband Markets, Report for EU Commission (2017), https://ec.europa.eu/competition/publications/ reports/kd0217687enn.pdf.
} 
operators zero-rate only the same particular application, nor any evidence for arrangements that would give exclusivity to a certain ISP or a specific content provider. Overall, the study reveals that there is little reason to believe that zero-rating gives rise to competition concerns. Indeed, while it seems to be relatively easy to identify the potential effects that zero-rating may have on choice of ISP and choice of content, hence on competition amongst ISPs and content providers, "it is much more difficult to show that, on balance, the effects of zero-rating are material and, in particular, of such a magnitude that competition concerns would be justified"61. Competition concerns would require the presence of market power at some level and the inability of competitors to replicate the underlying arrangement. This scenario and related potential foreclosure effects of zero-rating mainly arise in the case of operator-owned content ${ }^{62}$.

In summary, while it is undisputed that zero-rating practices may affect downstream (ISPs) and upstream (content providers) market competition, the aforementioned studies confirm that, because of the different characteristics of these offers and the different scenarios in which they may take place, it is impossible to predict whether they will raise significant concerns or whether procompetitive benefits will outweigh anticompetitive restrictions. Therefore, their assessment should require an ex post case-bycase investigation, rather than an ex ante regulatory ban.

Indeed, from a competition policy perspective, even if we consider the hypothesis of an exclusivity arrangement between an ISP and a content provider, at least three different scenarios may emerge. Firstly, let us suppose that an ISP reaches a zero-rating agreement for a "must have" content: this offer may promote downstream competition, but at the same time raise risks of foreclosure (both downstream and upstream) if the ISP has market power. In a second scenario, the ISP has market power, but the zero-rating offer comes from a new content provider: the agreement may promote upstream competition, allowing the newcomer to compete more aggressively against incumbent content providers. Finally, a dominant ISP may decide to zero-rate its own content: as mentioned in the study conducted by DotEcon, Aetha Consulting and Oswell and Vahida for the European Commission, this scenario is the most worrisome, because of the potential foreclosure effects it may generate. Nonetheless, these competitive risks

\footnotetext{
${ }^{61}$ Ibid., 136.

${ }^{62}$ Ibid., 138.
} 
are not different from those traditionally analysed by antitrust authorities in any scenario of vertical integration. Therefore, even in this last hypothesis, it is still unclear what the advantages of an ex ante regulatory prohibition over an expost antitrust enforcement are.

\section{Concluding remarks}

The recent Telenor decision has refuelled the debate on the limits and advantages of net neutrality, notably on the controversial added value of an ex ante regulatory intervention instead of the traditional ex post enforcement of antitrust rules.

Zero-rating offers indeed reflect the ambiguous competitive effects of discriminatory practices. While they unquestionably affect competition among both content and broadband providers, it is however impossible to establish in advance whether their purported exclusionary effects outweigh their potential pro-competitive benefits. Because of the different features of these offers and the different scenarios in which they may occur, zero-rating may foster broadband consumption, promote product differentiation and enhance competition, both downstream and upstream. Such programmes may allow end-users to tailor their internet services and can be used to better exploit network effects on certain services, consequently raising the number of subscriptions, to the ultimate benefit of both consumers and social welfare. Economic analysis has shown that even sponsored data plans can lead to similar beneficial effects. Nonetheless, by allowing broadband providers to make the consumption of some data packets less expensive than others, zero-rating offers are basically at odds with the net neutrality principle of non-discrimination, hence are banned, regardless of their actual exclusionary effects.

For these reasons, if the Telenor case has confirmed the contrast between zero-rating and the European net neutrality rules, it has at the same time made apparent the need for reforming the regulation to ensure an actual effects-based case-by-case analysis instead of a blanket prohibition.

\section{References}

Australian Competition and Consumer Commission. Digital platforms inquiry. 2019.

https://www.accc.gov.au/focus-areas/inquiries-ongoing/digital-platforms-inquiry.

BEREC. Guidelines on the Implementation by National Regulators of European Net Neutrality Rules. BoR. 2016.

BEREC. Guidelines on the Implementation of the Open Internet Regulation. BoR. 2020. 
BEREC. Report on the Implementation of Regulation (EU) 2015/2120 and BEREC Net Neutrality Guidelines. BoR. 2020.

Bourreau Marc, Frago Kourandi, and Tommaso Valletti. "Net neutrality with competing internet platforms". Journal of Industrial Economics 63, no. 1 (2015): 30.

Bundesnetzagentur. Net Neutrality in Germany Annual Report 2017/2018. 2018. https:// www.bundesnetzagentur.de/SharedDocs/Downloads/EN/Areas/Telecommunications/ Companies/MarketRegulation/NetNeutrality/NetNeutralityInGermanyAnnualReport 2017_2018.pdf?__blob=publicationFile\&v=2.

Canadian Radio-Television and Telecommunications Commission. Telecom Regulatory Policy. 2017. https://crtc.gc.ca/eng/archive/2017/2017-104.htm.

Carlton, Dennis W. and Randal C. Picker. "Antitrust and regulation”. In Economic Regulation and its Reform, edited by Nancy L. Rose. University of Chicago Press, 2014. Carrillo, Arturo J. "Having your cake and eating it too? Zero-rating, net-neutrality, and international law". Stanford Technology Law Review 19 (2016): 364.

Choi, Jay P., Doh-Shin Jeon, and Byung-Cheol Kim. "Net neutrality, network capacity, and innovation at the edges". The Journal of Industrial Economics 66, no. 1 (2018): 172.

Department of Telecommunications of India. Regulatory Framework on Net Neutrality. 2018. https://dot.gov.in/net-neutrality.

DotEcon, Aetha Consulting and Oswell and Vahida. Zero-Rating Practices in Broadband Market. Report for EU Commission (2017). https://ec.europa.eu/competition/publications/reports/kd0217687enn.pdf.

European Commission. Proposal for a Regulation on contestable and fair markets in the digital sector (Digital Markets Act).COM(2020) 842 final, 2020.

Gans, Joshua and Michael L. Katz. "Weak versus strong net neutrality: Corrections and extensions”. Journal of Regulatory Economics 50 (2016): 99.

Gautier, Axel and Robert Somogyi. "Prioritization vs. zero-rating: Discrimination on the internet". International Journal of Industrial Organization 73 (2020).

Gerpott, Torsten J. "Zero-rating arrangements of mobile Internet access service providers - An analysis of main factors shaping the need for regulatory interventions". Telecommunications Policy 42, no. 6 (2018): 489.

Greenstein, Shane, Martin Peitz, and Tommaso Valletti. "Net neutrality: A fast lane to understanding the trade-offs". The Journal of Economic Perspectives 30, no. 2 (2016): 127.

Hazlett, Thomas W. and Joshua D. Wright. "The effect of regulation on broadband markets: Evaluating the empirical evidence in the FCC's 2015 'Open internet' order”. Review of Industrial Organization 50 (2017): 487.

Hoernig, Steffen and Francisco Monteiro. "Zero-rating and network effects". Economics Letters 186 (2020). 
Hooton, Christopher A. "Testing the economics of the net neutrality debate". Telecommunications Policy 44, no. 5 (2020).

Inceoglu, Firat and Xingyi Liu. "Multiproduct price discrimination with quantity limits: An application to zero-rating”. Economics Letters 180 (2019): 41.

Jeitschko, Thomas D., Soo J. Kim, and Aleksandr Yankelevich. "Zero-rating and vertical content foreclosure”. DICE Discussion Paper No. 317 (2019), https://www.econstor. eu/bitstream/10419/200151/1/1668746867.pdf

Jullien, Bruno and Wilfried Sand-Zantman. "Internet regulation, two-sided pricing, and sponsored data”. International Journal of Industrial Organization 58 (2018): 31.

Katz, Michael L. "Wither U.S. net neutrality regulation?". Review of Industrial Organization 50 (2017): 441.

Krämer, Jan and Martin Peitz. “A fresh look at zero-rating”. Telecommunications Policy 42, no. 7 (2018): 501.

Kobayashi, Bruce H. and Joshua D. Wright. "Antitrust and ex-ante sector regulation". The Global Antitrust Institute, Report on the Digital Economy (2020): 865. https://gaidigitalreport.com.

Melamed, A. Douglas and Andrew W. Chang. "What thinking about antitrust law can tell us about net neutrality”. Colorado Technology Law Journal 15, no. 1 (2016): 93.

Ofcom. Monitoring Compliance with the EU Net Neutrality Regulation. 2018 https://www. ofcom.org.uk/research-and-data/internet-and-on-demand-research/net-neutrality.

Ofcom. Monitoring Compliance with the EU Net Neutrality Regulation. 2020. https:// www.ofcom.org.uk/research-and-data/internet-and-on-demand-research/ net-neutrality.

Ohlhausen, Maureen K. "Antitrust over net neutrality: Why we should take competition in broadband seriously”. Colorado Technology Law Journal 15 no. 1 (2016): 119.

Pai,Ajit.Statement.2018.https://www.fcc.gov/document/fcc-releases-restoring-internetfreedom-order/pai-statement.

Peitz, Martin and F. Schuett. "Net neutrality and inflation of traffic". International Journal of Industrial Organization 46 (2016): 16.

Reggiani, Carlo and Tommaso Valletti. "Net neutrality and innovation at the core and at the edge". International Journal of Industrial Organization 45 (2016): 16.

Sylvain, Olivier. "Integrative information platforms: The case of zero-rating". Georgetown Law Technology Review 2, no. 2 (2018): 360.

Tardiff, Timothy J. "Net neutrality: Economic evaluation of market developments". Journal of Competition Law \& Economics 11, no. 3 (2015): 701.

Telecom Regulatory Authority of India. "Prohibition of discriminatory tariffs for data services regulations”. (2016). https://www.trai.gov.in/notifications/press-release/ trai-releases-prohibition-discriminatory-tariffs-data-services. 
Yoo, Christopher S. "Avoiding the pitfalls of net uniformity: Zero rating and non-discrimination". Review of Industrial Organization 50 (2017): 509.

Yoo, Christopher S. "Beyond network neutrality". Harvard Journal of Law \& Technology 19, no. 1 (2005): 1.

UK Competition and Markets Authority. A new pro-competition regime for digital markets. Advice of the Digital Markets Taskforce. 2020. https://www.gov.uk/cma-cases/ digital-markets-taskforce.

U.S. House of Representatives, Subcommittee on Antitrust, Commercial, and Administrative Law. Investigation of Competition in Digital Markets. Majority Staff Reports and Recommendations. 2020. https://judiciary.house.gov/uploadedfiles/ investigation_of_competition_in_digital_markets_majority_staff_report_and_recommendations.pdf.

van Schewick, Barbara. "Towards an economic framework for network neutrality regulation”. Journal on Telecommunications \& High Technology Law 5, no. 2 (2006):329.

Vogelsang, Ingo. "Net neutrality regulation: Much ado about nothing?". Review of Network Economics 17, no. 3 (2019): 225.

Wireless Telecommunications Bureau. Policy Review of Mobile Broadband Operators' Sponsored Data Offerings for Zero-Rated Content and Services. 2017. https://www.fcc. gov/document/release-report-policy-review-mobile-zero-rating-practices. 